\title{
КРИТЕРИАЛЬНАЯ ОЦЕНКА КАК ПРИНЦИПИАЛЬНАЯ ОСНОВА МЕХАНИЗМА УПРАВЛЕНИЯ ЭКОНОМИЧЕСКОЙ УСТОЙЧИВОСТЬЮ ПРОМЫШЛЕННОГО ПРЕДПРИЯТИЯ
}

\author{
(c) 2018 Арошидзе Алёна Амирановна \\ старший преподаватель \\ Сибирский государственный университет путей сообщения \\ 630049, г. Новосибирск, ул. Д. Ковальчук, д. 191 \\ E-mail: aroshidzealyona@gmail.com
}

Рассмотрены основные составляющие механизма управления экономической устойчивостью и обоснована ключевая роль критериальной оценки в его рамках. Представлены разработанные методики оценки уровня экономической устойчивости и распознавания стадий кризиса по критериям.

Ключевые слова: экономическая устойчивость, механизм управления, надежность, динамичность, оценка уровня, вероятность потери устойчивости

Одним из ключевых ориентиров для оценки и осуществления управления, направленного на достижение наилучшего режима деятельности промышленного предприятия, является экономическая устойчивость [1]. Целесообразность и первоочередность использования такого ориентира объясняется тем фактом, что обеспечение экономической устойчивости создает условия для устойчивого развития промышленного предприятия, которое в современных условиях, как правило, обозначается в качестве генеральной цели стратегического управления. Однако, как отмечают И.А.Баев, А.В.Шмидт, в связи с мировым экономическим кризисом конца первого десятилетия 21 века для современных промышленных предприятий стала очевидной и более того вышла на первый план «проблема отсутствия аппарата адекватного управления с позиции экономической устойчивости» [2]. Ещё в большей степени актуализирует данную проблему и задачи, связанные с ее разрешением, текущая ситуация в сфере российской экономики.

В нашем понимании, экономическая устойчивость промышленного предприятия - это свойство сохранять свое положение в пространстве стратегического режима, формируемое посредством взаимосогласованного управления, направленного на противодействие и приспособление к воздействиям среды (негативным и позитивным соответственно), и характеризующееся через нахождение показателей предприятия в разрезе его функциональных элементов не ниже предельно допустимого уровня с позиции таких критериев, как надежность и динамичность.

Обеспечение экономической устойчивости промышленного предприятия требует структурированной управленческой деятельности, осуществляемой в рамках соответствующего механизма управления. Поскольку обеспечение ЭУ создает условия для устойчивого развития, которое, как показывает практика, обозначается в качестве генеральной стратегической цели, внедрение механизма управления ЭУ должно осуществляться в существующий организационно-экономический механизм управления промышленным предприятием. Механизм управления экономической устойчивостью должен включать:

- блок информационно-методического обеспечения; аналитический блок;

- блок актуализации аналитической информации;

- блок разработки и принятия управленческих решений.

Говоря об алгоритме применения данного механизма, отметим соблюдение принципа непрерывности: шаг 1: действия в рамках блока информационно-методического обеспечения; шаг 2: действия в рамках аналитического блока; шаг 3: действия в рамках блока актуализации аналитической информации; шаг 4: действия в рамках блока разработки и принятия управленческих решений; шаг 5: возвращение к блоку 1. Ключевое место в механизме управления экономической устойчивостью должна занимать ее комплексная оценка и анализ. Очевидно, что 
оценка и анализ экономической устойчивости для промышленного предприятия представляют собой способ его познания, который состоит из ряда последовательно осуществляемых действий (в рамках определенной методики). Более того, рассматривать оценку и анализ экономической устойчивости необходимо исключительно в рамках механизма управления, так как только таким образом обеспечивается их адекватность для принятия решений по корректировке управленческих действий в той или иной ситуации, которая выявляется посредством проведения соответствующих процедур. Полученная по итогам оценки информация должна характеризоваться такой смысловой нагрузкой, чтобы, включаясь обратно в процесс управления, способствовала максимально полному соблюдению особо важных принципов преемственности и вариативности управляющих воздействий. В этой связи оценка экономической устойчивости должна осуществляться по двум выделенным критериям - надежности и динамичности. В таком случае экономическая устойчивость исследуется как управленческая категория, и разрешается возможное противоречие между собственной динамикой значений показателей и их соответствием нормативным значениям.

Для этих целей разработан двухэтапный методический подход к критериальной оценке экономической устойчивости (табл.): непосредственно оценка экономической устойчивости и распознавание стадий кризиса по критериям (вероятность потери экономической устойчивости). Кратко рассмотрим каждую из них.

Разработанная методика оценки экономической устойчивости обладает следующими преимуществами. Во-первых, двухкомпонентность оценки по критериям и не сведение показателей устойчивости по ним в один комплексный показатель, т.к. это в большей мере отражает картину деятельности предприятия с позиции экономической устойчивости и служит ориентиром для принятия управленческих решений в рамках механизма управления. Во-вторых, учет при проведении расчетов закона наименьшей устойчивости, что отражено в получении отрицательного значения по составляющей $\left(\mathrm{D}_{\mathrm{Hp}}\right.$ или что тоже самое $\left.\mathrm{KЭУ}_{\mathrm{C}-}\right)$ в случае ее нахождения в неравновесном состоянии, и его включения в формулу для расчета итогового коэффициента экономической устойчивости с сохранением знака минус.
Для того чтобы механизм управления экономической устойчивостью характеризовался большей результативностью, критериальная оценка, составляющая основу для выработки управленческих решений, должна также быть направлена на определение вероятности потери экономической устойчивости, которая рассматривается как кризисное состояние. Методика, направленная на решение данной задачи, является вторым элементом представляемого методического подхода. Мы предлагаем развить методические положения улавливания сигналов скрытого кризиса (Коротаева Ю.В. [3], Броило Е.В. [4]), но именно в контексте экономической устойчивости промышленного предприятия для разработки собственной методики.

Во-первых, масштабность (ширина охвата направлений деятельности) и интенсивность (глубина) кризисных явлений на предприятии предлагаем оценивать по показателям экономической устойчивости предприятия в разрезе его функциональных элементов по критериям - надежности и динамичности (в отличии от анализа только финансового состояния предприятия), что позволит выявить и оценить кризисные явления по сферам их возникновения.

Во-вторых, полностью соглашаясь с Коротаевой Ю.В., будем придерживаться обоснованной ей градации стадий кризиса, но с выделением еще одной промежуточной стадии до наступления острого кризиса: потенциальный, скрытый (фактически означает предкризисную стадию), прогрессирующий, переходящий в острый кризис (т.е. до наступления критического уровня потери экономической устойчивости), острый кризис (характеризуется критическим уровнем потери экономической устойчивости и полной потерей). Таким образом, оценка сигналов будет свидетельствовать не только о скрытом, но и об остром кризисе, если такой уже имеет место или развивается.

В-третьих, предлагаем применять десятибалльную шкалу выраженности сигналов кризиса с тем, чтобы оценивать степень выраженности кризисных процессов на всех уровнях экономической устойчивости и по всем тенденциям (например, низкий уровень, несмотря на наличие тенденции к повышению показателей в его рамках, все же говорит о кризисных явлениях на предприятии, причем достаточно явно выраженных).

B-четвертых, анализ снижения показателей 
предлагается заменить анализом тенденций по уровням экономической устойчивости. Анализ производится за определенный период, чтобы изучить тенденции в динамике для получения более полной картины, посредством расчета коэффициента Спирмена и избежать детального рассмотрения случайного характера изменения значений показателей. Сформированный набор сигналов, в свою очередь, позволяет обнаружить и оценить стадии кризиса, и, самое главное, провести анализ и предотвратить его развитие.
Практическое применение методического подхода к критериальной оценке и анализу экономической устойчивости, элементами которого являются две вышеописанные методики, доказало его основополагающую роль в рамках механизма управления, тем самым совершенствуя его и в совокупности с его практической направленностью по внедрению в общий организационно-экономический механизм управления предприятием отличая от ранее существующих подобных механизмов. Это обусловлено тем

Таблица. Критериальная оценка экономической устойчивости

\begin{tabular}{|c|c|}
\hline \multicolumn{2}{|c|}{ 1. Методика оценки экономической устойчивости (ЭУ) по критериям } \\
\hline Формирование системы показателей & $\begin{array}{l}\text { построение многоуровневой структурной схемы } \\
\text { (дерева свойств); свойство 0-го уровня - ЭУ, свойство } \\
1 \text { 1-го уровня - расстояния до предельно допустимого } \\
\text { уровня (до нижней границы равновесия первой сте- } \\
\text { пени) в разрезе функциональных элементов (ФЭ), т.е. } \\
\text { устойчивости составляющих, свойства 2-го уровня - } \\
\text { показатели в разрезе ФЭ, определяющие степень } \\
\text { равновесия }\end{array}$ \\
\hline $\begin{array}{l}\text { Определение весовых коэффициентов составляющих } \\
\text { ЭУ и показателей в рамках них }\end{array}$ & $\begin{array}{l}\text { определение значений коэффициента весомости по } \\
\text { каждой составляющей ЭУ, коэффициента весомо- } \\
\text { сти ее показателей и интегрального коэффициента } \\
\text { весомости (ИКВ) }\end{array}$ \\
\hline \multicolumn{2}{|c|}{ Сбор и расчет значений показателей } \\
\hline $\begin{array}{l}\text { Нормирование показателей: определение грании рав- } \\
\text { новесий, отнесение показателей к их степеням }\end{array}$ & $\begin{array}{l}\text { определение баллов по значениям и баллов с учётом } \\
\text { ИКВ; баллы присуждаются от } 1 \text { до } 4 \text { в зависимости от } \\
\text { степени равновесия: } 1 \text { - неравновесное состояние } \\
\text { и т.д. }\end{array}$ \\
\hline $\begin{array}{l}\text { Вычисление обобщенного показателя по функциональ- } \\
\text { ным элементам, определяющего степень равновесия по } \\
\text { элементу }\end{array}$ & $\begin{array}{l}\text { расчет по каждой составляющей ЭУ суммарного ко- } \\
\text { личества баллов, а также минимально и максимально } \\
\text { возможного суммарного количества баллов с ИКВ; } \\
\text { определение границы степеней равновесия и нерав- } \\
\text { новесного состояния по ФЭ }\end{array}$ \\
\hline $\begin{array}{l}\text { Расчет удаленности обобщенного показателя до пре- } \\
\text { дельно допустимого уровня по всем ФЭ-определение } \\
\text { устойчивости составляющих ЭУ (финансовой -ФУ, } \\
\text { рыночной - РУ, производственной ПУ, кадровой КУ) }\end{array}$ & 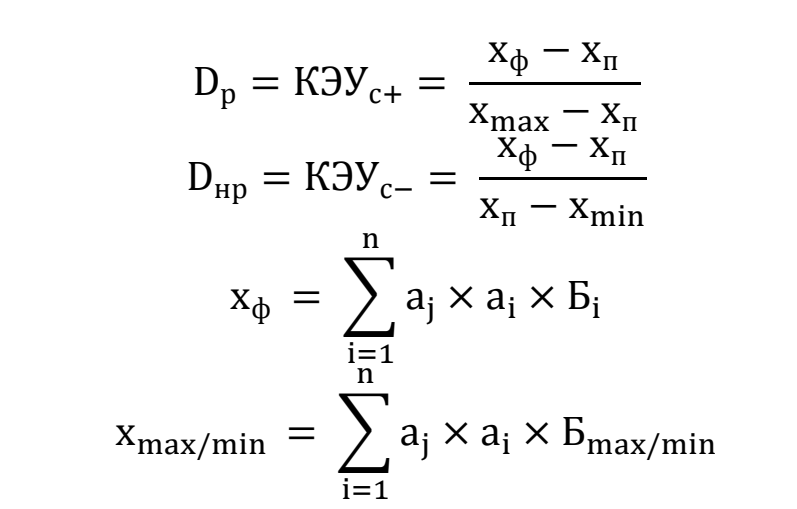 \\
\hline \multicolumn{2}{|c|}{ 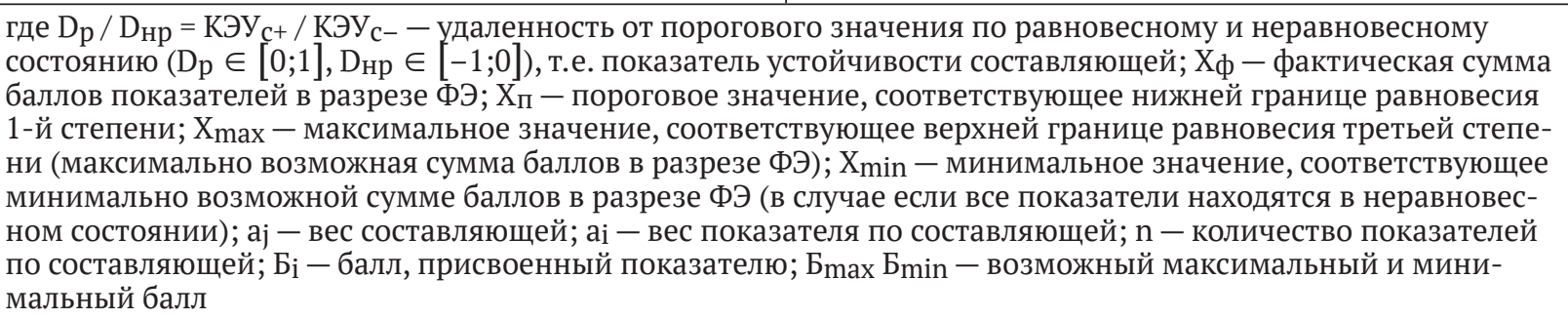 } \\
\hline
\end{tabular}




\section{Окончание таблицы}

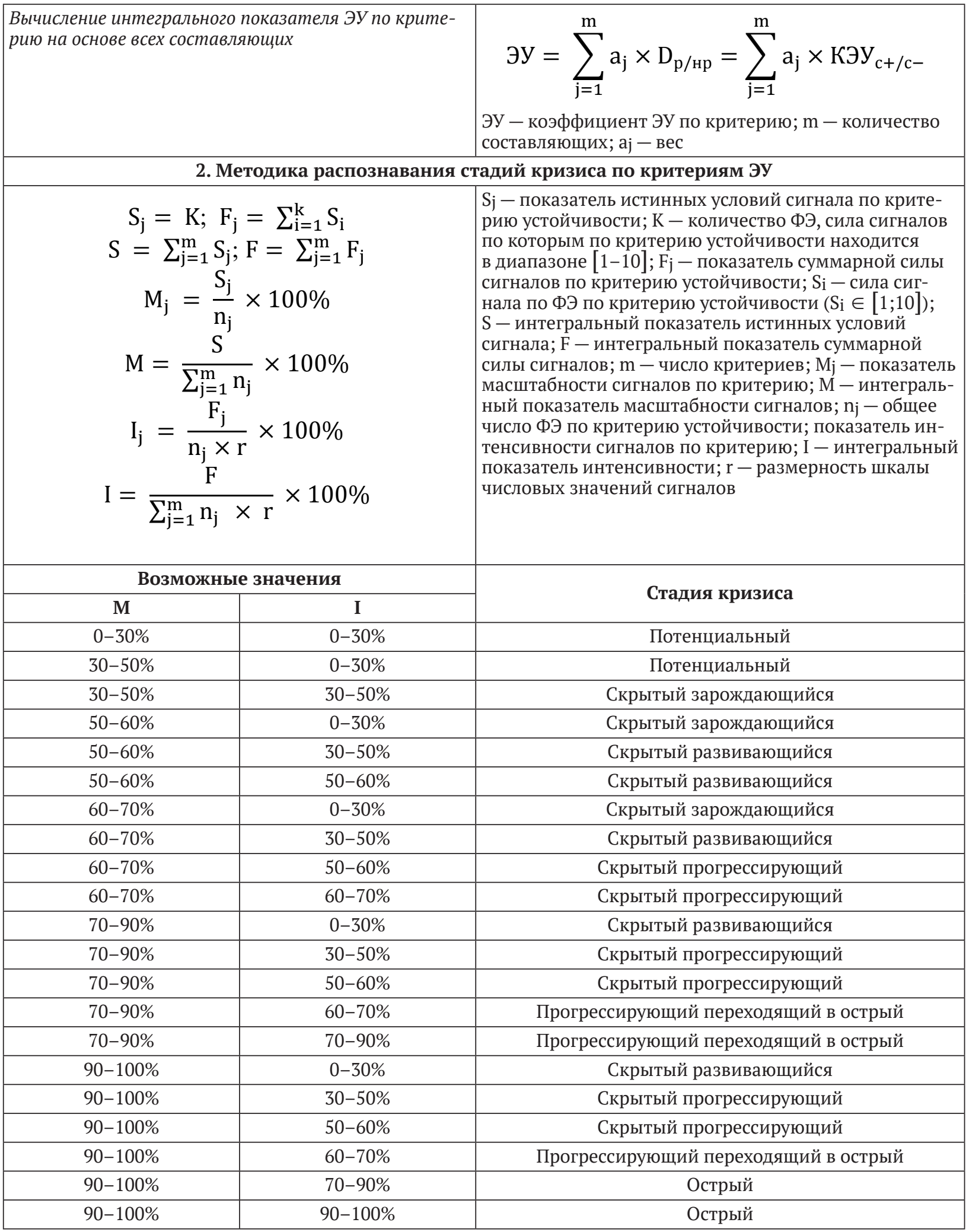


фактом, что данный подход позволяет: осуществлять расчет показателей, которые характеризуют экономическую устойчивость; определять ее уровень; определять тенденции показателей экономической устойчивости и устойчивости составляющих, определять на их основе силу кризисных сигналов, осуществлять расчет масштабности и интенсивности сигналов; опреде- лять стадии кризиса с позиции экономической устойчивости; анализировать показатели, ее характеризующие по составляющим, и при необходимости определять принципы действий по корректировке управленческих действий для их повышения; моделировать и прогнозировать ЭУ по составляющим по критериям.

\section{Библиографический список}

1. Мисхожев Э.Р. Теория и методология управления экономической устойчивостью промышленных предприятий: автореф. дис. ... д-ра. экон. наук: 08.00 .05 (Текст) / Э.Р. Мисхожев. СПб, 2013. 40 с.

2. Баев И.А. Управление экономической устойчивостью предприятия в контексте повышения его конкурентоспособности (Текст) / И.А. Баев, А.В. Шмидт // Вестник УРФУ. Серия экономика и управление. 2012. № 3. C. 50-63.

3. Коротаева Ю.В. Разработка механизма выхода строительных организаций из скрытого кризиса: автореф. дис... канд. экон. наук: 08.00 .05 (Текст) / Ю.В. Коротаева. Спб.: Санкт-Петербургский государственный архитектурно-строительный университет. 2004. 18 с.

4. Броило Е.В. Методология управления экономической устойчивостью коммерческой организации на основе мониторинга кризисных процессов: автореф. дис... д-ра экон. наук: 08.00 .05 (Текст) / Е.В. Броило. Екатеринбург: Институт экономики Уральского отделения Российской академии наук, 2009. 47 с.

Поступила в редакцию 12.08.2018 